\title{
Introduction to the New Copolymer of Chloroprene and Acrylonitrile with Differentiated Properties
}

\author{
Mousumi De Sarkar $\mathbb{D}^{1},{ }^{1}$ Wataru Nishino, ${ }^{2}$ Yuhei Ishigaki, ${ }^{2}$ and Takashi Sunada ${ }^{2}$ \\ ${ }^{1}$ Elastomers Department, Denka Corporation, Louisiana Office, LaPlace, LA, USA \\ ${ }^{2}$ Elastomers Department, Denka Co. Ltd., Omi Plant, Japan \\ Correspondence should be addressed to Mousumi De Sarkar; mouds22@gmail.com
}

Received 30 March 2021; Revised 1 July 2021; Accepted 7 July 2021; Published 22 July 2021

Academic Editor: Li Zibiao

Copyright (c) 2021 Mousumi De Sarkar et al. This is an open access article distributed under the Creative Commons Attribution License, which permits unrestricted use, distribution, and reproduction in any medium, provided the original work is properly cited.

\begin{abstract}
The random copolymer of chloroprene and acrylonitrile is a newly developed rubber whose features and value propositions are not scientifically explored yet. This article focuses on the basic characterizations and properties of acrylonitrile-chloroprene rubber. Qualitative analyses through infrared (FTIR) and nuclear magnetic resonance ( $\left.{ }^{1} \mathrm{H}-\mathrm{NMR}\right)$ spectra confirm the presence of both the $-\mathrm{Cl}$ and $-\mathrm{CN}$ groups in the new rubber. As evidenced through differential scanning calorimetry (DSC) and dynamic mechanical thermal analysis (DMTA), the single glass transition temperature of acrylonitrile-chloroprene rubber reflects its monophasic random microstructure. While compared against commercial grades of chloroprene rubber (CR) and nitrile rubber (NBR), the new rubber provides a distinctive combination of properties that are not available with either of the elastomer alone. Acrylonitrile-chloroprene rubber demonstrates slightly lower specific gravity, an improved low-temperature compression set, higher flex-fatigue resistance, and lower volume swelling in IRM 903 and Fuel C to chloroprene rubber. As compared to nitrile rubber, the new copolymer shows appreciably better heat aging and ozone resistance. Good abrasion resistance, low heat buildup, and remarkably high flex-fatigue resistance indicate excellent durability of the acrylonitrile-chloroprene rubber under dynamic loading. Based on the preliminary results, it is apparent that the new copolymer can be a candidate elastomer for various industrial applications which demand good fluid resistance, high heat and low-temperature tolerances, good weatherability, and durability under static and dynamic conditions.
\end{abstract}

\section{Introduction}

Polychloroprene (commonly known as chloroprene rubber $(\mathrm{CR}))$ is one of the first synthetic elastomers known to humanity. It remains a vital elastomer even today for a plethora of industrial applications such as gaskets, tubing, seals, Orings, hoses, belts, and weather-resistant products such as wet suits. It is also used as a base resin in adhesives and coatings. Aqueous dispersion (latex) of chloroprene rubber finds its usages in dipped goods (such as gloves), foams, etc. Due to the presence of the electronegative chlorine adjacent to the unsaturation in the polymer backbone, CR offers good weather, ozone, and aging resistance, a balance of mechanical properties, decent resistance to various fluids, and good inherent flame resistance [1]. The CR homopolymer, however, shows limited flexibility at subambient temperatures, owing to its tendency toward low-temperature-induced crystallization [2].

The acrylonitrile-butadiene rubber, commonly known as nitrile rubber (NBR), another polar synthetic elastomer, on the other hand, demonstrates outstanding oil resistance, however, with limited aging and ozone resistance [3]. Furthermore, it does not have inherent flame resistance like CR. The main applications of NBR are in fuel hoses, gaskets, rollers, and other products in which high oil resistance is required. Commercially available NBR grades typically are with $15 \%$ to $50 \%$ acrylonitrile content, with advantages and trade-offs in properties varying appreciably with the level of 
acrylonitrile [4]. Increasing the polar acrylonitrile content increases the oil resistance and strength of the rubber but decreases its elasticity at low temperatures.

There have been several initiatives to merge the performance benefits of CR and NBR, primarily through the melt blending process [5-7] to address a long-standing requirement for cost-effective heat- and oil-resistant elastomeric materials with excellent weatherability. Such materials may be promising for applications in oil and gas, automotive, and other allied industries.

While some of the key attributes of both CR and NBR can be transferred into their physical amalgams, the resultant blends demonstrate functional challenges with reduced resilience, limited flex cracking, and poor ozone resistance, particularly with an increasing proportion of NBR in the composition. The melt blends of CR and NBR are reported to be incompatible [8], with two distinct glass transition temperatures [9]. Blends of carboxylated NBR (XNBR) and CR are also immiscible and incompatible and have poor mechanical properties due to the low interfacial interactions $[10,11]$. The blend of NBR, CR, and polyvinyl chloride (PVC) has also been studied [12]. As expected, the introduction of PVC reduces the elasticity, and the NBR/CR/PVC ternary blend with a compromised compression set acts more like a thermoplastic elastomer rather than a rubber. Preparation and properties of chlorinated acrylonitrile-butadiene rubber (Cl-NBR) with a maximum of $22 \%$ chlorine content have also been reported [13]. While the oil resistance property of Cl-NBR is significantly improved through chlorination, the thermal stability of Cl-NBR decreases appreciably with an increase in chlorine content [14].

With the desire to produce a copolymer of chloroprene that incorporates a small portion of the unsaturated acrylonitrile monomer for the primary purpose of augmenting the oil resistance while still demonstrating the critical traits of $\mathrm{CR}$, a new rubber was conceptualized and developed. The new acrylonitrile-chloroprene rubber was synthesized through a controlled emulsion polymerization process, comprising chloroprene as the predominant comonomer and acrylonitrile monomer as the minor component [15]. The acrylonitrilechloroprene rubber has the chemical structure as below:

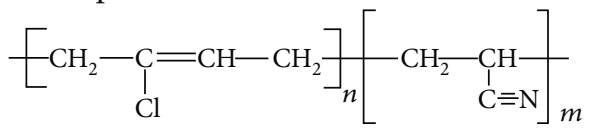

Acrylonitrile-chloroprene rubber is a brand-new polymer with a distinctive chemical composition. The new rubber is primarily developed to integrate some particular characteristics of two major industrial rubbers: CR and NBR. It is, therefore, fundamentally intriguing to recognize the functionalities and uniqueness of acrylonitrile-chloroprene rubber. To the best of our knowledge, there has not been any published literature available on acrylonitrile-chloroprene rubber so far. This preliminary report introduces acrylonitrilechloroprene rubber, outlining what it is, and provides an overview of its properties. The article is aimed at setting a background to assess the potential applicability of this new rubber in diverse industrial areas. The basic characterizations and some features of the copolymer are highlighted here. The properties of the copolymer are compared against commercial grades of $\mathrm{CR}$ and $\mathrm{NBR}$, used as internal benchmarks.

\section{Experimental}

2.1. Raw Materials. The new acrylonitrile-chloroprene rubber (designated throughout the text as NCR), with acrylonitrile content under $20 \%$ by mass, was synthesized through a proprietary emulsion polymerization technique at $5-20^{\circ} \mathrm{C}$ [15]. The aqueous dispersion of the copolymer was then freeze-coagulated at $-20^{\circ} \mathrm{C}$ and drawn into a thin sheet. After washing with water, followed by drying at $130^{\circ} \mathrm{C}$ for $15 \mathrm{mins}$, the sheet was gathered into a rope and then chopped to the solid rubber chips. The acrylonitrile-chloroprene rubber (commercially launched as Evolmer ${ }^{\circledR}$ by Denka Co. Ltd.) has a Mooney viscosity $\left(\mathrm{ML}_{1+4}\right.$ at $\left.100^{\circ} \mathrm{C}\right)$ of 55 . The chloroprene rubber (CR) homopolymer used here for comparison is a commercially available mercaptan-modified generalpurpose grade, M-40, by Denka Co. Ltd., with a Mooney viscosity $\left(\mathrm{ML}_{1+4}\right.$ at $\left.100^{\circ} \mathrm{C}\right)$ of 52 . The commercial-grade nitrile rubber (NBR) used in this work is N230S from Japan Synthetic Rubber Co. Ltd., Japan. NBR has 34-36\% acrylonitrile content and a Mooney viscosity $\left(\mathrm{ML}_{1+4}\right.$ at $\left.100^{\circ} \mathrm{C}\right)$ of about 55 . The common compounding additives used in all formulations include a processing aid (stearic acid from Kao Chemicals Industry Co. Ltd.); an antioxidant $\left(4,4^{\prime}\right.$-bis $(1,1$ dimethylbenzyl)diphenylamine, Nocrac ${ }^{\mathrm{TM}} \mathrm{CD}$ from Ouchi Shinko Chemical Industrial Co. Ltd., Japan); an antidegradant ( $N$-(1,3-dimethylbutyl)- $N$ '-phenyl-p-phenylenediamine, Santoflex ${ }^{\mathrm{TM}}$ 6PPD from Eastman); a plasticizer (polyether-ester type, RS-700 from Adeka, Japan); zinc oxide (ZnO) (Zinc Oxide II from Sakai Chemical Industry Co. Ltd., Japan) as a curing activator; and medium active Fast Extrusion Furnace (FEF) carbon black (N550 from Asahi Carbon Co., Ltd., Japan) as a reinforcing filler. In addition, CR- and NCR-based compounds contained magnesium oxide (MgO, Kyowamag $^{\mathrm{TM}} 150$ from Kyowa Chemical Industry Co., Ltd., Japan), primarily as a neutralizer of hydrogen chloride that may be liberated from the polymer during processing or service, thereby rendering improved stability in the compounds. The primary vulcanization accelerator used for CR and NCR was trimethylthiourea (Nocceler ${ }^{\mathrm{TM}}$ TMU from Ouchi Shinko Chemical Industrial Co. Ltd., Japan). As a typical practice, NBR was vulcanized utilizing a combination of elemental sulfur (Hosoi Chemical Industry, Japan) as a crosslinking agent and Nocceler ${ }^{\mathrm{TM}}$ DM (dibenzothiazyl disulfide from Ouchi Shinko Chemical Industrial Co. Ltd., Japan) as a vulcanization accelerator. All the raw materials were used as procured without further purification.

2.2. Characterization of the Gum Rubber. Fourier Transform Infrared (FTIR) spectra were acquired by scanning the thin film specimens in the wavenumber range of $400-4000 \mathrm{~cm}^{-1}$ with a resolution of $2 \mathrm{~cm}^{-1}$ at room temperature $\left(23^{\circ} \mathrm{C}\right)$ using a PerkinElmer spectrophotometer $\left(\right.$ Frontier $\left.^{\mathrm{TM}}\right)$. Nuclear magnetic resonance (NMR) measurement was carried out using the ECX 400 spectrometer (from JEOL Ltd., Japan) operating at $400 \mathrm{MHz}$ at $30^{\circ} \mathrm{C}$. The liquid-state proton NMR $\left({ }^{1} \mathrm{H}-\right.$ NMR) was conducted after dissolving samples in deuterated 
TABLE 1: Basic compounding formulations used for acrylonitrilechloroprene rubber (NCR), chloroprene rubber (CR), and nitrile rubber (NBR).

\begin{tabular}{|c|c|c|c|c|}
\hline \multirow{2}{*}{ Ingredients } & \multirow{2}{*}{ Key functions } & \multicolumn{3}{|c|}{ Quantities in phr } \\
\hline & & NCR & CR & NBR \\
\hline Rubber & - & 100 & 100 & 100 \\
\hline Stearic acid & Processing aid & 0.5 & 0.5 & 0.5 \\
\hline Nocrac $^{\mathrm{TM}}$ CD & Antioxidant & 3 & 3 & 3 \\
\hline Carbon black N550 & Reinforcing filler & 50 & 55 & 62 \\
\hline RS-700 & Plasticizer & 10 & 10 & 10 \\
\hline $\mathrm{MgO}(\# 150)$ & Acid receptor & 4 & 4 & 0 \\
\hline $\mathrm{ZnO}$ & Curing activator & 5 & 5 & 5 \\
\hline Santoflex ${ }^{\mathrm{TM}} 6 \mathrm{PPD}$ & Antidegradant & 1 & 1 & 1 \\
\hline Nocceler ${ }^{\mathrm{TM}} \mathrm{TMU}$ & Accelerator & 1 & 1 & 0 \\
\hline Sulfur & Crosslinking agent & 0 & 0 & 1.5 \\
\hline Nocceler $^{\mathrm{TM}} \mathrm{DM}$ & Accelerator & 0 & 0 & 1.5 \\
\hline
\end{tabular}

chloroform (chloroform-d or $\mathrm{CDCl}_{3}$ ) solvent. The data reported was the average of 512 scans at the pulse repetition time of $\sim 7 \mathrm{~s}$. Gel permeation chromatography (GPC) (Model HLC-8220GPC from Tosoh Corporation) was used to measure the molecular weight (number average molecular weight $\left(M_{\mathrm{n}}\right)$ and weight average molecular weight $\left.\left(M_{\mathrm{w}}\right)\right)$ and the polydispersity index $\left(\mathrm{PDI}=M_{\mathrm{w}} / M_{\mathrm{n}}\right)$ using tetrahydrofuran (THF) as solvent following ISO 22768 standard. The glass transition temperature $\left(T_{\mathrm{g}}\right)$ of the gum rubber was determined through a differential scanning calorimeter (DSC) (Mettler Toledo DSC1) according to ISO 22768 under nitrogen atmosphere using a heating rate of $10^{\circ} \mathrm{C}$. Measurement of specific gravity of raw rubber was done at $23^{\circ} \mathrm{C}$ following ISO 2781 standard.

2.3. Processing. The compounding formulations used for NCR, CR, and NBR are shown in Table 1. The level of carbon black was slightly varied among elastomers to achieve the comparable hardness values of the resultant vulcanizates. The compounding was done in two stages. In the first stage, the mixing of rubber with all the ingredients except $\mathrm{ZnO}$ and the other curing agents was carried out in a lab-scale Banbury mixer (MS-1.7 IM from Minami Senju Seisakusho Ltd.) at a load factor of $0.65-0.70$, at 30 to $40^{\circ} \mathrm{C}$, with a rotational speed of $50 \mathrm{rpm}$. After homogeneous mixing of about 5-6 mins, the compound was discharged from the Banbury mixer at a temperature not exceeding $120^{\circ} \mathrm{C}$, flattened out using a two-roll mill, and cooled down to room temperature. In the second stage of compounding, $\mathrm{ZnO}$ and the other curatives were added to the rubber mix in an 8-inch tworoll mill with a nip gap of $\sim 3 \mathrm{~mm}$ at $40^{\circ} \mathrm{C}$, mixed for about 5 mins, and then sheeted out. Except for the compression set, all samples were cured at $170^{\circ} \mathrm{C}$ for 20 mins using an electrically heated hydraulic press. The cylindrical specimens (thickness $12.5 \pm 0.5 \mathrm{~mm}$ ) for the compression set were press-cured at $170^{\circ} \mathrm{C}$ for 30 mins, followed by a secondary curing process while subjected to $175^{\circ} \mathrm{C}$ for $2 \mathrm{hrs}$ inside an air oven.
2.4. Testing. The Mooney viscosity $\left(\mathrm{ML}_{1+4}\right)$ of the prevulcanized rubber stock was measured following ISO 289-1:2015 using a Mooney viscometer (SMV-301) from Shimadzu Corporation, Japan, at $100^{\circ} \mathrm{C}$. The Mooney scorch test was performed at $125^{\circ} \mathrm{C}$ per ISO 289-2:2015 using the same machine. The cure behavior of rubber compounds was evaluated using an Automatic Rotorless Rheometer (ARR) (Model RLR-3 from Toyo Seiki Seisaku-sho, Ltd.) at $170^{\circ} \mathrm{C}$ for 30 mins according to ISO 6502. The measured parameters are $M_{\mathrm{L}}$ (minimum torque), $M_{\mathrm{H}}$ (maximum torque), $t_{\mathrm{S} 2}$ (time to 2 units of torque increase above the minimum), and $t_{10}$ and $t_{90}$ (time corresponding to $10 \%$ and $90 \%$ of the maximum achievable torque). The cure rate index (CRI), a parameter that indicates the speed of curing reaction, was calculated from the rheometric data following the equation below:

$$
\mathrm{CRI}=\frac{100}{\left(t_{90}-t_{\mathrm{S} 2}\right)}
$$

The tensile properties were determined using an automated universal testing machine (UTM, Model Strograph AE from Toyo Seiki Seisaku-sho, Ltd.) using dumbbell specimens of $2 \mathrm{~mm}$ thick, per ISO 37:2017. All tests were carried out at room temperature $\left(25 \pm 2^{\circ} \mathrm{C}\right)$, and the tensile data reported were the average of 4 tests. ISO 34-1 standard was followed to measure tear strength with a 90-degree angle specimen using the UTM at room temperature $\left(23^{\circ} \mathrm{C}\right)$ with a $500 \mathrm{~mm} / \mathrm{min}$ crosshead speed and with a minimum of 3 repeats. Hardness (durometer, Shore A) of the rubber vulcanizate was measured as per ISO 48-1:2018 with a minimum of 5 repeats per sample. Compression set measurements were carried out using cylindrical disc specimens of thickness $12.5 \pm 0.5 \mathrm{~mm}$ and diameter of $29 \mathrm{~mm}$, following the ISO 815:2019 method. Specimens were kept under 25\% compression for 72 hours at different temperatures, then allowed to recover at room temperature. The compression set is expressed as the percentage of the original deformation not retrieved after the recovery period: 0 percent indicating full recovery and 100 percent indicating no recovery. The data reported were the average of a minimum of 2 repeats.

Abrasion resistance of vulcanized rubber samples was assessed at room temperature $\left(25 \pm 2^{\circ} \mathrm{C}\right)$ using a DIN Abrasion Tester from Toyo Seiki Seisaku-sho, Ltd., Japan, following ISO 4649 standard. The test piece with a diameter and thickness of $16 \mathrm{~mm}$ and $6 \mathrm{~mm}$ was subjected to a $10 \mathrm{~N}$ load. The speed of the rotating drum was $40 \pm 1 \mathrm{rpm}$. After 84 rotations (after $\sim 3$ mins), the volumetric loss was measured and reported as the average of 3 sets of tests.

The heat buildup characteristics of vulcanized rubber samples were assessed using a Goodrich Automatic Flexometer from Ueshima Seisakusho Ltd., Japan, following ISO 4666 standard at a base temperature of $50^{\circ} \mathrm{C}$ and conditioning time of $30 \mathrm{mins}$. The static load applied was $30 \mathrm{lbs}$, the deflection was set at 0.2 inches, and the test frequency used was $30 \mathrm{~Hz}$. The temperature difference $(\Delta T)$ before and after the test run of 30 mins was monitored and reported here as an average of 3 data points. 

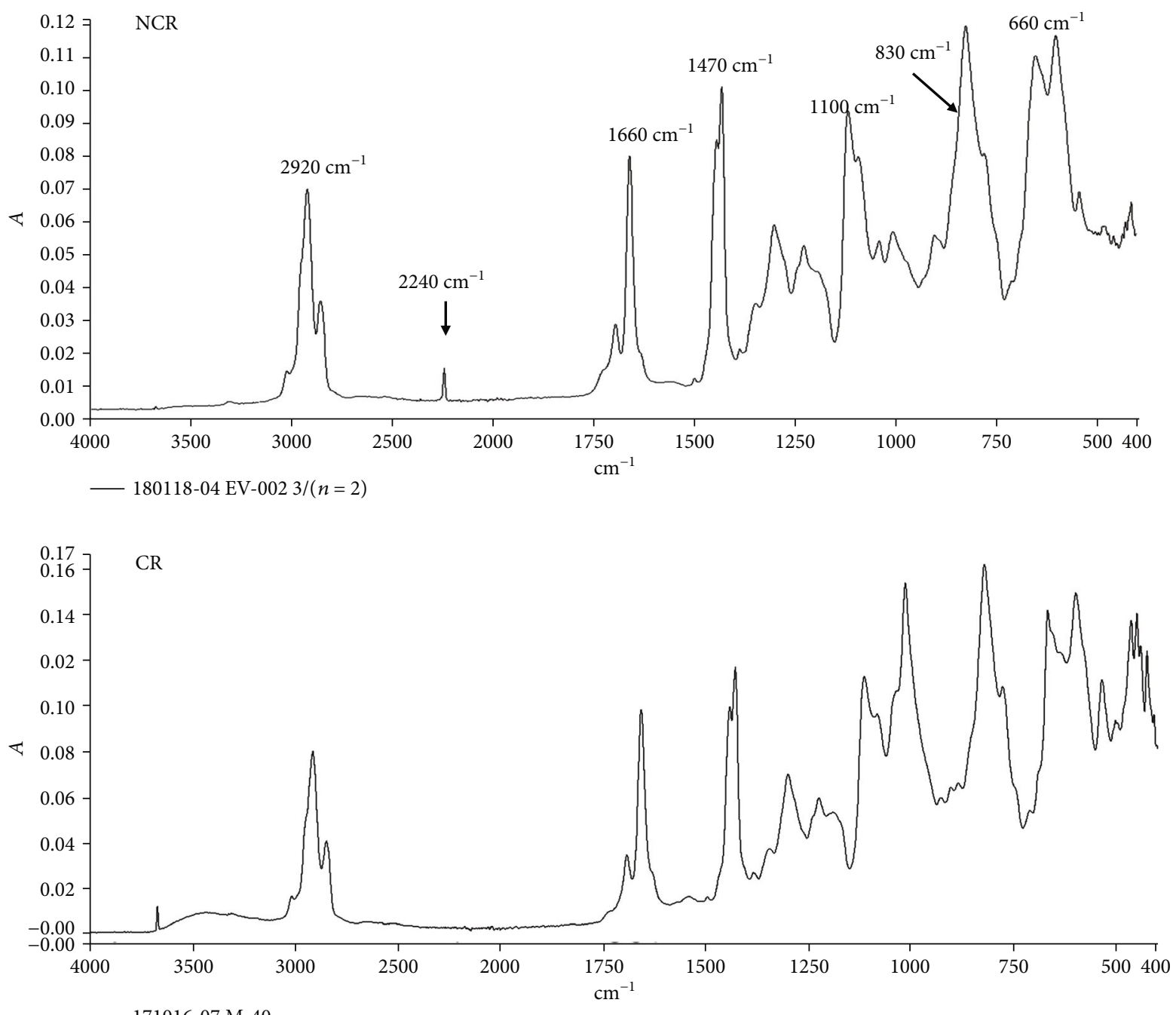

- 171016-07 M-40

FIGURE 1: FTIR spectra of acrylonitrile-chloroprene rubber (NCR) and chloroprene rubber (CR).

Resistance of rubber vulcanizates toward cracking was ascertained using a DeMattia flexing fatigue tester (Model TM-1513 from Ueshima Seisakusho Ltd.) operating at $100^{\circ} \mathrm{C}$ at a frequency of $5 \mathrm{~Hz}$ using ISO 132:2017 standard. The test result reported, as the number of cycles to failure, was the average of a minimum of 5 repeats.

Dynamic mechanical thermal analysis (DMTA) of the rubber vulcanizates was carried out using a Rheovibron Dynamic Viscoelastomer (Model Rheo-1021). Tests were carried out under tension mode at a frequency of $10 \mathrm{~Hz}$ with a strain amplitude of $30 \mu \mathrm{m}$. The rectangular samples $\left(45 \times 4.5 \times 2.0 \mathrm{~mm}^{3}\right)$ were first cooled to $-150^{\circ} \mathrm{C}$ and then subsequently heated at a rate of $5^{\circ} \mathrm{C} / \mathrm{min}$ to $150^{\circ} \mathrm{C}$ in the test run.

The impact of thermal aging on rubber vulcanizates was studied using a controlled air-circulating oven at temperatures ranging from $100^{\circ} \mathrm{C}$ to $140^{\circ} \mathrm{C}$ for different periods following ISO 188:2011 standard. The tensile strength (TS), elongation at break (EB), and hardness (HS) of the specimen were measured after accelerated aging at the specified temperature and time.

Resistance of rubber vulcanizates toward different test fluids was monitored following ISO 1817:2015 by measuring the volume swelling and the changes in tensile properties of the test specimens after complete immersion into fluids over a range of temperature and time. The volume swelling, expressed as a percentage of volume change, was calculated using the following equation:

$$
\Delta V=\frac{\left(M_{3}-M_{1}\right)}{d \times\left(M_{1}-M_{2}\right)} \times 100
$$

where $\Delta V$ is the change in volume (\%), $M_{1}$ is the initial mass of the specimen in air $(\mathrm{g}), M_{2}$ is the initial mass of the specimen in test fluid (g), $M_{3}$ is the mass of the specimen in air after immersion $(\mathrm{g})$, and $d$ is the density of immersion liquid at standard laboratory room temperature $(\mathrm{g} / \mathrm{ml})$.

Changes in tensile properties due to exposure of fluids expressed as percentage changes of tensile strength and elongation at break were calculated based on the following equation:

$$
\Delta P=\left[\frac{A-O}{O}\right] \times 100
$$




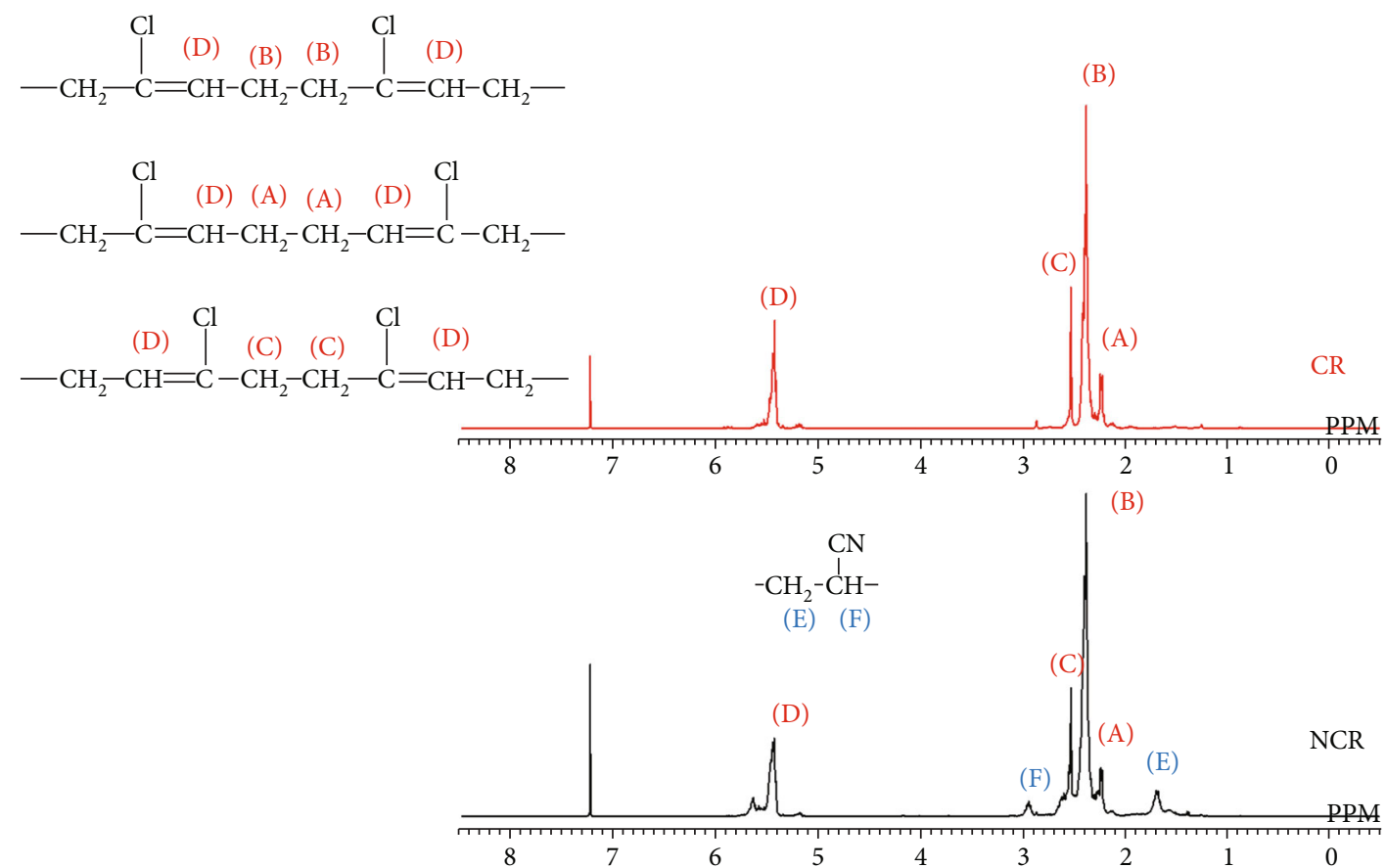

FIGURE 2: ${ }^{1} \mathrm{H}-\mathrm{NMR}$ spectra of acrylonitrile-chloroprene rubber (NCR) and chloroprene rubber (CR).

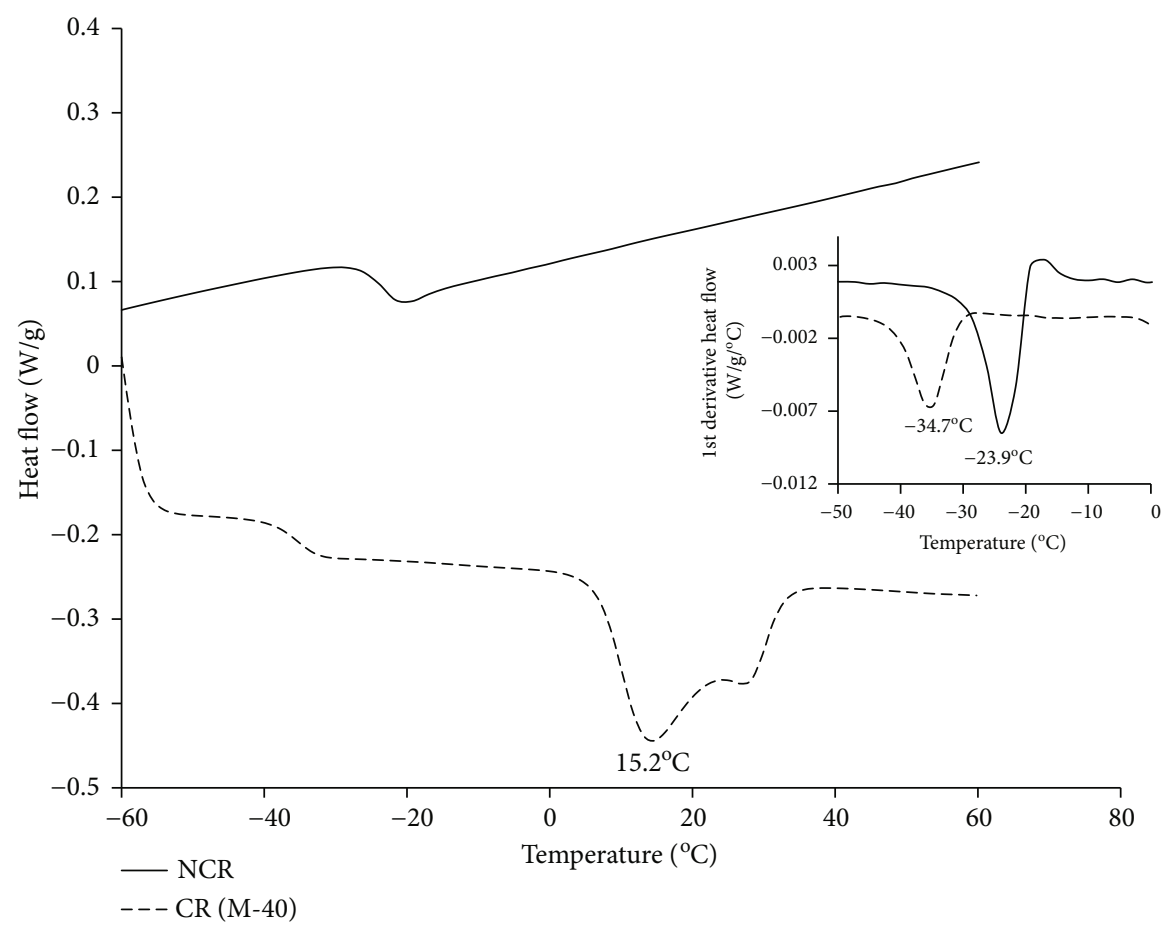

FIGURE 3: DSC results of acrylonitrile-chloroprene rubber (NCR) and chloroprene rubber (CR). The inset shows the 1st derivative plots in the glass transition regions.

where $\Delta P$ is the change in the property (\%), $O$ is the original value, and $A$ is the value after aging.

Ozone resistance of the rubber vulcanizate under dynamic operational conditions was monitored using a UVC Ozone Aging Tester from Toyo Seiki Seisaku-sho, Ltd., following
ISO $1431-2$ standard. The test was carried out at $40^{\circ} \mathrm{C}$ with an ozone concentration of $50 \mathrm{pphm}$ while subjecting the test pieces to $0-20 \%$ sinusoidal tensile strain at a frequency of $0.5 \mathrm{~Hz}$ for different periods. The specimens were periodically examined for cracking. 
TABLE 2: Molecular weight and specific gravity of acrylonitrilechloroprene rubber (NCR) and chloroprene rubber (CR).

\begin{tabular}{lcc}
\hline & NCR & CR \\
\hline Molecular weight (by GPC) & & \\
$M_{\mathrm{n}}$ & $14.6 \times 10^{4}$ & $17.6 \times 10^{4}$ \\
$M_{\mathrm{w}}$ & $34.4 \times 10^{4}$ & $44.8 \times 10^{4}$ \\
PDI $\left(M_{\mathrm{w}} / M_{\mathrm{n}}\right)$ & 2.4 & 2.5 \\
Specific gravity & 1.19 & 1.23 \\
\hline
\end{tabular}

\section{Results and Discussion}

Figure 1 shows the Fourier Transform Infrared (FTIR) spectrum of acrylonitrile-chloroprene rubber (NCR). The spectrum of the chloroprene rubber (CR) homopolymer is also provided as a reference. The characteristic absorption band at $2240 \mathrm{~cm}^{-1}$ in NCR, attributed to the stretching vibration of $-\mathrm{C} \equiv \mathrm{N}$ groups, validates the presence of the acrylonitrile moiety in the copolymer. NCR shows two prominent peaks at around $830 \mathrm{~cm}^{-1}$ and $660 \mathrm{~cm}^{-1}$, respectively. Those coincide with the signature peaks assigned to $\mathrm{C}-\mathrm{Cl}$ stretching and bending vibrations found in chloroprene rubber (CR) $[16,17]$. The other prominent peaks in NCR are at $2920 \mathrm{~cm}^{-1}$ due to $\mathrm{C}-\mathrm{H}$ asymmetric stretching, at $\sim 1660 \mathrm{~cm}^{-1}$ due to $\mathrm{C}=\mathrm{C}$ stretching, at $\sim 1470 \mathrm{~cm}^{-1}$ due to $\mathrm{C}-\mathrm{H}$ bending, and at $1110 \mathrm{~cm}^{-1}$ assigned to $\mathrm{C}-\mathrm{C}$ stretching vibrations. Those characteristic peaks are also present in the CR homopolymer.

Figure 2 shows the ${ }^{1} \mathrm{H}-\mathrm{NMR}$ spectra of acrylonitrilechloroprene rubber (NCR) and the chloroprene rubber (CR) homopolymer. Four significant signals appeared at around $2.24,2.39,2.54$, and $5.4 \mathrm{ppm}$ in both the rubbers. The peak assignments in Figure 2 are made based on the NMR data reported in the literature for CR [18]. The minor peaks at 2.40 and $2.88 \mathrm{ppm}$ and the cluster of peaks at 5.15$5.24 \mathrm{ppm}$ are not assigned here for clarity. In NCR, two new peaks at 2.95 and $1.71 \mathrm{ppm}$ confirm the incorporation of the acrylonitrile units. The strong singlet signal that appeared at $7.26 \mathrm{ppm}$ in both the rubbers is due to the solvent, $\mathrm{CDCl}_{3}$ [19]. The quantitative microstructural analysis through either FTIR or NMR is beyond the scope of this technical contribution and hence is not reported.

The differential scanning calorimetry (DSC) result of acrylonitrile-chloroprene rubber (NCR) in comparison to the chloroprene rubber (CR) homopolymer is shown in Figure 3. As observed, a single glass transition temperature at $-24^{\circ} \mathrm{C}$ was found for NCR. The single glass transition temperature confirms acrylonitrile-chloroprene rubber as a random copolymer of acrylonitrile and chloroprene (Figure 3). The glass transition temperature of the chloroprene rubber is around $-35^{\circ} \mathrm{C}$. The positive shift in the glass transition temperature in the acrylonitrile-chloroprene rubber from the chloroprene rubber homopolymer is attributed to the increase in polarity through the incorporation of acrylonitrile ( $-\mathrm{C} \equiv \mathrm{N}$ groups), making the macromolecular chain movements rather difficult. CR shows a broad endothermic peak with an onset at $6.8^{\circ} \mathrm{C}$ and a peak temperature at $15.2^{\circ} \mathrm{C}$, asso- ciated with the melting of crystallites. No such peak is seen in NCR. The bulky $-\mathrm{C} \equiv \mathrm{N}$ groups in acrylonitrile-chloroprene rubber (NCR) are likely to provide interruptions to the regularity sequence along the polymer chains, thereby preventing crystallization. It is known that with the increasing size of the side groups, it becomes progressively more difficult for the polymer to fold and align itself along the crystal growth direction, thus reducing the ability and likelihood to crystallize [20].

The molecular weight and the molecular weight distribution values of acrylonitrile-chloroprene rubber (NCR) as obtained through gel permeation chromatography (GPC) are shown in Table 2 . As observed, the new rubber demonstrates high molecular weight $\left(>10^{5}\right)$ with a reasonably narrow molecular weight distribution or polydispersity index (PDI) of around $\sim 2.4$. The molecular weights $\left(M_{\mathrm{n}}\right.$ and $\left.M_{\mathrm{w}}\right)$ and PDI of CR are marginally higher than that of NCR. The specific gravity of acrylonitrile-chloroprene rubber at 1.19 is slightly lower than that of the CR homopolymer (1.23) (Table 3).

The Mooney viscosity and Mooney scorch time of the prevulcanized acrylonitrile-chloroprene rubber (NCR) compound in comparison to $\mathrm{CR}$ and $\mathrm{NBR}$ are shown in Table 3. The Mooney viscosity of the NCR compound, as measured at $100^{\circ} \mathrm{C}$, has been found to be equivalent to that of NBR but appreciably lower than that of CR. In the CR compound, at the test condition of Mooney viscosity measurement, the crosslinking reaction might have already started, causing the steep rise of compound viscosity from about 52 units for the virgin rubber to 70 units in the compound during the test. The shortest Mooney scorch time in CR also reflects the possibility of premature crosslinking reaction during the test. The scorch times of NCR and CR compounds, measured at $125^{\circ} \mathrm{C}$, were $17.7 \mathrm{mins}$ and 9.4 mins, respectively, even though the same crosslinking agents were used in both. Considerably higher scorch time in NCR reveals its superior processing safety compared to CR. NBR cured with sulfur also showed reasonably good processing safety at the given test condition.

The torque-time dependencies of acrylonitrilechloroprene rubber (NCR) during curing alongside CR and $\mathrm{NBR}$ as assessed through the rheometer (ARR) are shown in Figure 4. All the three elastomers evaluated here indicate a stable state of cure with well-defined plateau regions in the cure curves. NCR demonstrates the most prolonged onset of cure and CR, the shortest. However, the CR compound shows the highest yield of cure as evidenced through the maximum torque value achieved, followed by NCR and $\mathrm{NBR}$ at $170^{\circ} \mathrm{C}$. The key parameters obtained through the rheometer test are shown in Table 3 . The minimum torque $\left(M_{\mathrm{L}}\right)$ of NCR and NBR is equivalent at $0.1 \mathrm{~N} \cdot \mathrm{m}$, while CR offers a much higher value $(0.2 \mathrm{~N} \cdot \mathrm{m}) . M_{\mathrm{L}}$ represents the torque of the compounds in the cure curves before the onset of the vulcanization reaction. Therefore, $M_{\mathrm{L}}$ can supposedly be a measure of the viscosity of unvulcanized compounds. However, a much higher $M_{\mathrm{L}}$ value in $\mathrm{CR}$ may indicate that at the given test temperature of $170^{\circ} \mathrm{C}$, the cure might have already started in CR, causing the minimum torque to rise appreciably. This observation corroborates the considerably higher 
TABLE 3: Mooney viscosity, scorch, and cure characteristics of acrylonitrile-chloroprene rubber (NCR), chloroprene rubber (CR), and nitrile rubber (NBR).

\begin{tabular}{|c|c|c|c|}
\hline & NCR & $\mathrm{CR}$ & NBR \\
\hline Mooney viscosity of compounds $\left(\mathrm{ML}_{1+4}\right), 100^{\circ} \mathrm{C}$ & 55 & 70 & 55 \\
\hline Scorch time $\left(t_{5}, \min \right), 125^{\circ} \mathrm{C}$ & 17.7 & 9.4 & 16.4 \\
\hline \multicolumn{4}{|l|}{ Rheometer (ARR) data, $170^{\circ} \mathrm{C}, 30$ mins } \\
\hline Minimum torque $\left(M_{\mathrm{L}}, \mathrm{N} \cdot \mathrm{m}\right)$ & 0.1 & 0.2 & 0.1 \\
\hline Maximum torque $\left(M_{\mathrm{H}}, \mathrm{N} \cdot \mathrm{m}\right)$ & 1.6 & 2.2 & 1.1 \\
\hline$M_{\mathrm{H}}-M_{\mathrm{L}}(\mathrm{N} \cdot \mathrm{m})$ & 1.5 & 2.0 & 1.1 \\
\hline$t_{\mathrm{S} 2}(\min )$ & 3.8 & 2.2 & 1.7 \\
\hline Time corresponds to $10 \%$ cure $\left(t_{10}, \min \right)$ & 3.5 & 2.1 & 1.5 \\
\hline Time corresponds to $90 \%$ cure $\left(t_{90}, \mathrm{~min}\right)$ & 9.7 & 5.6 & 4.7 \\
\hline Cure rate index $\left(\mathrm{min}^{-1}\right)$ & 16.9 & 29.4 & 33.3 \\
\hline
\end{tabular}

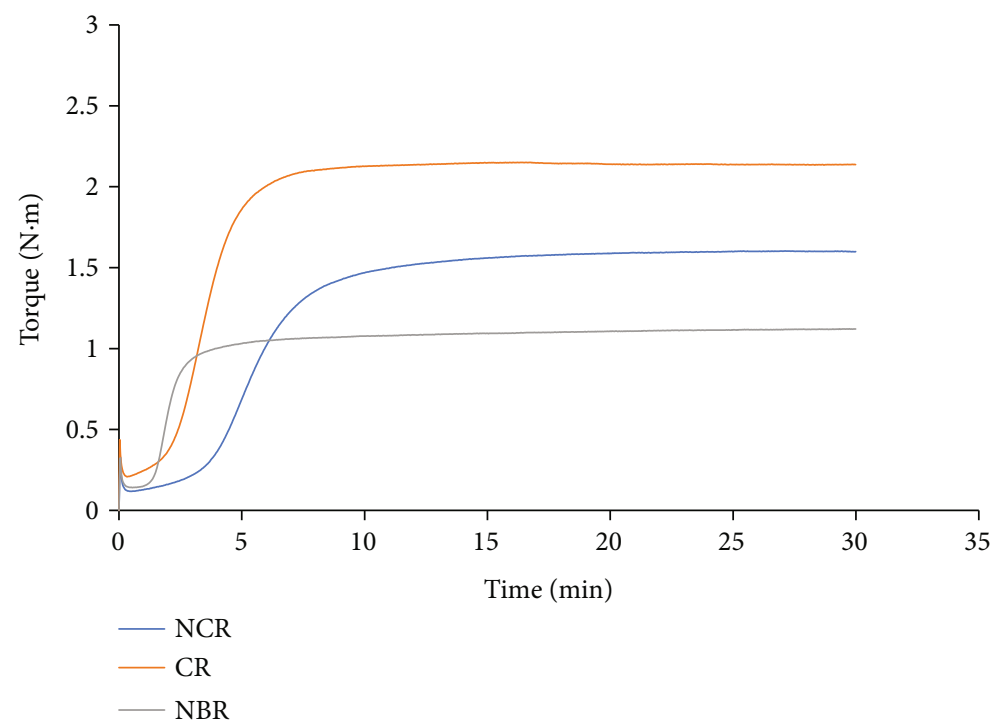

FIGURE 4: Rheometric cure curves of compounds of acrylonitrile-chloroprene rubber (NCR), chloroprene rubber (CR), and nitrile rubber (NBR).

TABle 4: Properties of vulcanizates of acrylonitrile-chloroprene rubber (NCR), chloroprene rubber (CR), and nitrile rubber (NBR).

\begin{tabular}{lccc}
\hline & NCR & CR & NBR \\
\hline Modulus at $100 \%$ elongation $(\mathrm{MPa})$ & 4.6 & 8.0 & 3.8 \\
Tensile strength $(\mathrm{MPa})$ & 21.5 & 22.3 & 19.6 \\
Elongation at break $(\%)$ & 337 & 228 & 411 \\
Hardness (Shore A) (units) & 72 & 73 & 71 \\
Tear strength $(\mathrm{N} / \mathrm{mm})$ & 53 & 55 & 68 \\
Abrasion resistance $(\mathrm{DIN})\left(\Delta V, \mathrm{~mm}^{3}\right)$ & 106 & 108 & 96 \\
Heat buildup $\left(\Delta T,{ }^{\circ} \mathrm{C}\right)$ & 43 & 35 & 70 \\
Flex-fatigue resistance at $100^{\circ} \mathrm{C}\left(\right.$ cycles $\left.\times 10^{4}\right)$ & $>200$ & 0.2 & 74 \\
\hline
\end{tabular}

Mooney viscosity found in the CR compound, even at $100^{\circ} \mathrm{C}$, compared to NCR and NBR. CR also demonstrates the highest $M_{\mathrm{H}}$ value and the largest difference in torque $\left(\Delta \mathrm{M}=M_{\mathrm{H}}-M_{\mathrm{L}}\right)$, followed by NCR and NBR. Even though the amount and type of curing systems remain invariant among NCR and CR compounds, NCR vulcanizates show about $25 \%$ lower $\Delta \mathrm{M}$ than $\mathrm{CR}$. In the rubber curing process through a rheometer, the $M_{\mathrm{H}}$ value is directly associated with the state of cure or the extent of chemical crosslinking of the polymer chains. $\Delta \mathrm{M}$ typically correlates to the crosslink density in the rubber vulcanizate [21]. Among the three rubbers, the largest $\triangle \mathrm{M}$ in $\mathrm{CR}$ indicates the highest level of crosslinking there. The cure kinetics, represented here by $t_{10}, t_{90}$, and cure rate index (CRI) values, are shown in Table 3 . The time that the rubber compound takes to reach the optimum state of cure $\left(t_{90}\right)$ at $170^{\circ} \mathrm{C}$ is longest in NCR at 9.7 mins, which is $\sim 42 \%$ more than that of the CR homopolymer $\left(t_{90}=5.6 \mathrm{mins}\right)$, even when using the same curing regimens. NBR, with sulfur curing, however, shows the lowest $t_{90}$ at 4.7 mins. Among the three rubbers evaluated, the rate of cure or CRI is lowest in NCR at the given compounding formulations and conditions. Considering the elevated rate of cure and higher crosslink density achieved in CR, it can be inferred that TMU as a standalone accelerator is perhaps more effective to the CR homopolymer than with the copolymer, NCR. In $\mathrm{CR}$, the curing process using $\mathrm{ZnO}$ and a 


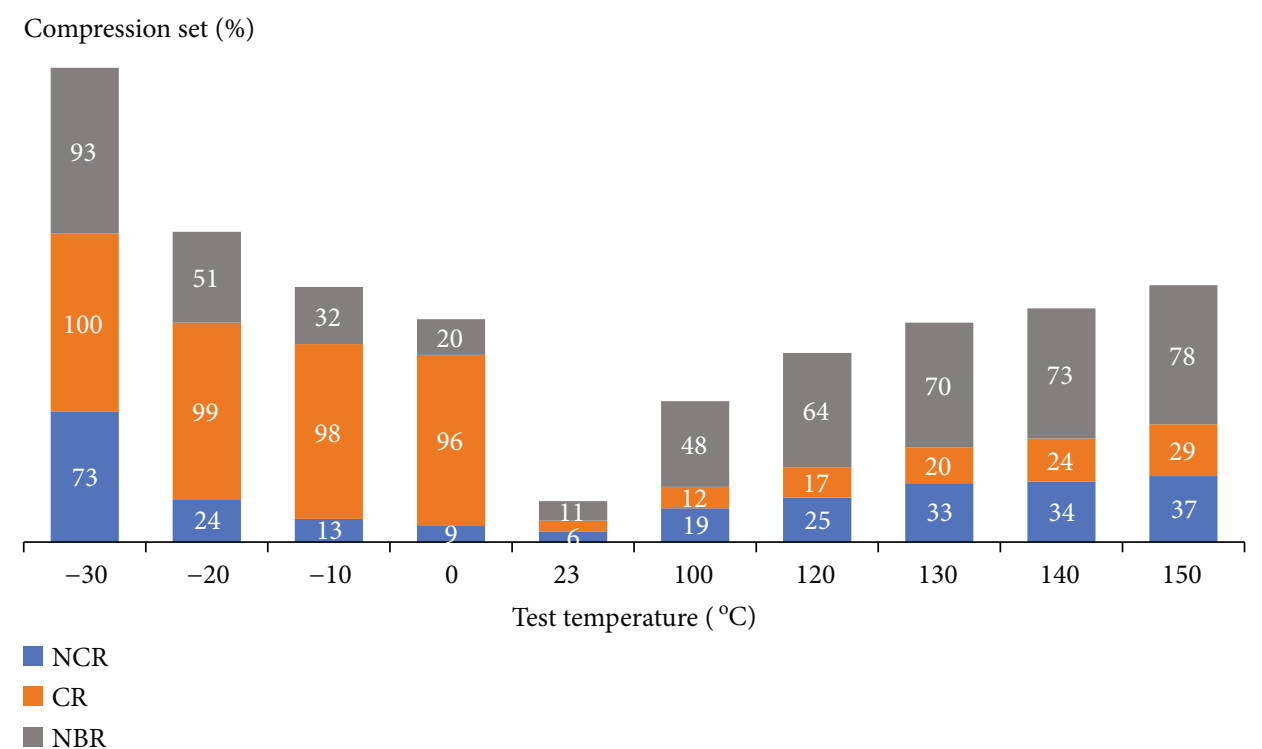

FIGURE 5: Compression set (\%) of vulcanizates of acrylonitrile-chloroprene rubber (NCR), chloroprene rubber (CR), and nitrile rubber (NBR) after $72 \mathrm{hrs}$ at different test temperatures.

thiourea-based accelerator predominantly occurs through allylic double bonds [22]. NCR being a copolymer of chloroprene and acrylonitrile, the allylic groups are presumably reduced in quantity there than that present in the CR homopolymer. As a result, the crosslink density in NCR becomes lesser than that in the CR homopolymer. It may be noted that, like any other elastomer, the rate and state of cure of the NCR compound can also be altered using different curing agents. The detailed investigation on the impact of different curatives on NCR properties is outside the purview of the current technical contribution and will be reported elsewhere.

The properties of acrylonitrile-chloroprene rubber (NCR) vulcanizates and those of CR and NBR are shown in Table 4. CR demonstrates the highest 100\% modulus between the three elastomers, which may be correlated to its highest crosslink density. The NCR compound exhibits lower modulus and tensile strength and slightly higher elongation at break values than $\mathrm{CR}$.

Tear strength indicates the capacity of the vulcanizates to resist cutting, chipping, and tearing actions during service. The tear strength values of NCR and CR are comparable. NBR, on the other hand, shows the highest tear strength among the three rubbers, presumably because of the sulfur crosslinking system used therein. Sulfur-cured rubber vulcanizates containing more elastic $-\mathrm{C}-\mathrm{S}_{x}-\mathrm{C}$ - bonds typically exhibit improved tear strength than the vulcanizates crosslinked via -C-C- bonds with lesser flexibility [23].

The acrylonitrile-chloroprene rubber (NCR) has comparable resistance toward abrasion to $\mathrm{CR}$ with similar volumetric losses (Table 4). Slightly lesser volume loss during abrasion has been seen in the NBR vulcanizate. Even though the NBR vulcanizate has a lower level of crosslinking, leading to lower modulus and higher elongation values, it still offers slightly better abrasion resistance than CR and NCR. Incremental improvement in abrasion resistance may be attrib- uted to the somewhat higher level of carbon black present in the NBR compound to provide comparable hardness to CR and NCR (Table 1).

Heat buildup is a significant characteristic for the durability assessment of rubber products exposed to dynamic loads. Rubbers exhibit hysteretic behavior under cyclic loadings that, combined with very low thermal conductivity, leads to a temperature rise. The heat buildup in acrylonitrile-chloroprene rubber (NCR) $\left(\Delta T=43^{\circ} \mathrm{C}\right)$ is a bit higher than that in CR $\left(\Delta T=35^{\circ} \mathrm{C}\right)$ (Table 4). But the heat buildup in NCR is substantially lower (more than $25^{\circ} \mathrm{C}$ ) than that in NBR $\left(\Delta T=70^{\circ} \mathrm{C}\right)$, under identical test conditions, indicating its potentially superior performance in dynamic applications over NBR. Polysulfide crosslinks in NBR are easy to cleave under high temperatures or stress [3]. Therefore, the scissions of polysulfide crosslinks in the NBR vulcanizate may have happened during the Goodrich Automatic Flexometer test, yielding the reduction of its crosslink density. Subsequently, the elastic modulus might have decreased to some extent, resulting in increased heat buildup in NBR.

As evidenced in Table 4, the flex-fatigue resistance of the acrylonitrile-chloroprene rubber (NCR) compound has been found to be remarkably superior to that of CR and NBR, while measured at $100^{\circ} \mathrm{C}$. The marked improvement in flex-fatigue resistance of NCR, particularly in comparison to that of the CR homopolymer, may be correlated to its difference in crosslink density while cured with the same vulcanization system. As evidenced through rheometer (ARR) results, CR has a higher crosslink density than acrylonitrile-chloroprene rubber. High crosslink density in the rubber compound or the too tight polymer network is often associated with increased stiffness and reduced efficiency to dissipate energy, leading to reduced flex-fatigue resistance [24]. The nature of crosslinks formed during vulcanization is known to influence fatigue properties as well [25]. The sulfur vulcanization system used in NBR may aid 

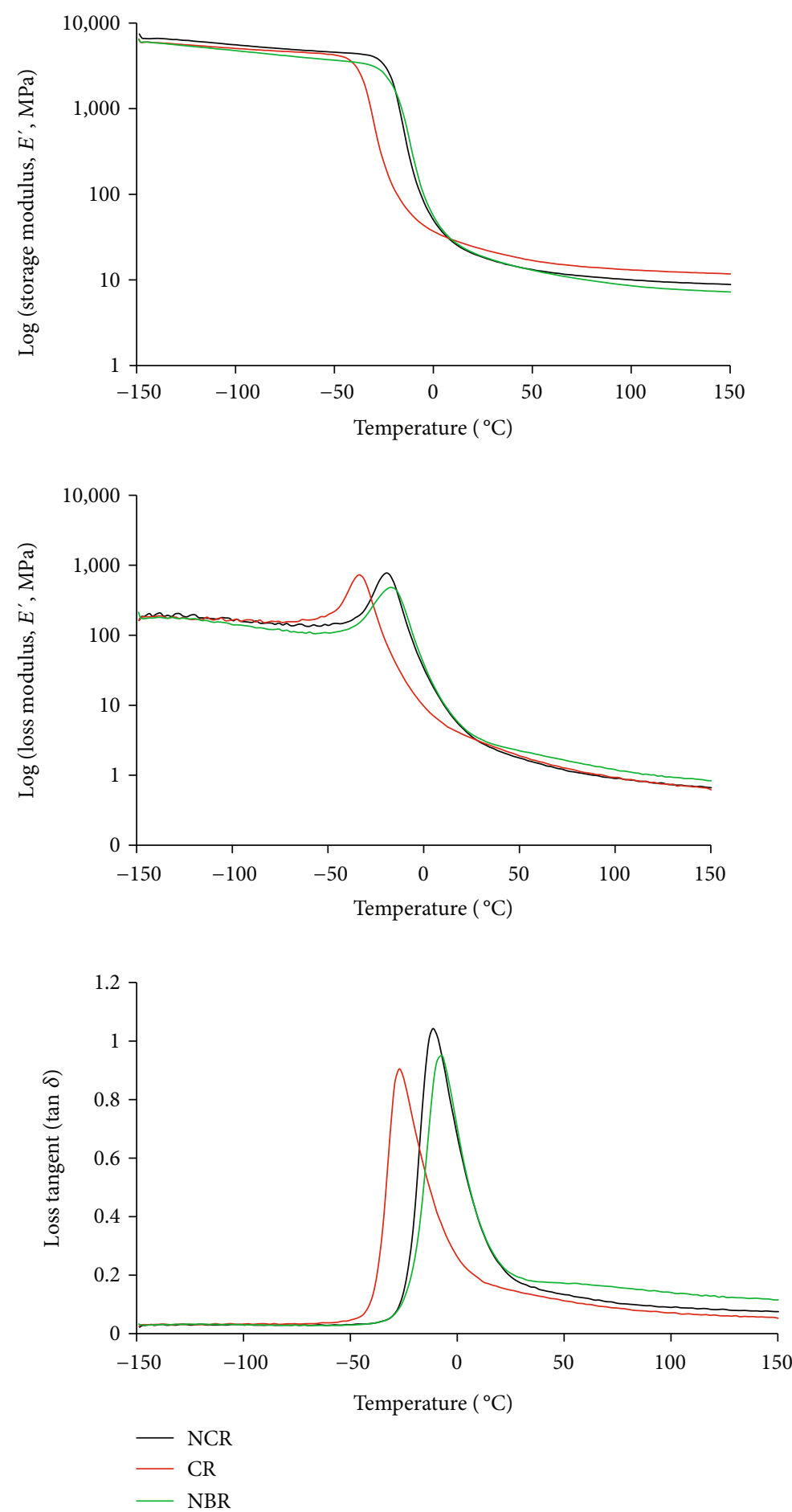

FIgURE 6: DMTA results on vulcanizates of acrylonitrile-chloroprene rubber (NCR), chloroprene rubber (CR), and nitrile rubber (NBR).

in its better flex-fatigue performance than $\mathrm{CR}$ that had $\mathrm{ZnO}$ as the activator and TMU as the accelerator for vulcanization. The more flexible polysulfide crosslinks (-C-S ${ }_{x}-\mathrm{C}$ - bonds) are known to offer better flex-fatigue resistance over -C-C- or -C-S- bonds in general $[26,27]$. The ability of the polysulfide crosslinks to cleave quickly and reform enables enhanced energy dissipation, thus offering a better fatigue life in rubber vulcanizates [28]. Even though NBR showed better flex-fatigue resistance than $\mathrm{CR}$, the test temperature of $100^{\circ} \mathrm{C}$ may still be high for NBR. In addition, we have seen appreciably high heat buildup in NBR under dynamic loading (Table 4), which further yields to local heating and may lead to degradation reactions. Once the degradation initiates, the subsequent loss of mechanical properties may cause the lowering of flex-fatigue resistance of NBR as compared to that of NCR. 
TABLE 5: Resistance to volume swelling ( $\Delta V$, \%) of vulcanizates of acrylonitrile-chloroprene rubber (NCR), chloroprene rubber (CR), and nitrile rubber (NBR).

\begin{tabular}{lcccc}
\hline Fluids & Test conditions & NCR & CR & NBR \\
\hline IRM 901 & $130^{\circ} \mathrm{C} \times 72 \mathrm{hrs}$ & $-5 \%$ & $+3 \%$ & $-8 \%$ \\
IRM 903 & $130^{\circ} \mathrm{C} \times 72 \mathrm{hrs}$ & $+21 \%$ & $+52 \%$ & $2 \%$ \\
Engine oil & $130^{\circ} \mathrm{C} \times 72 \mathrm{hrs}$ & $-4 \%$ & $+2 \%$ & $-7 \%$ \\
Fuel C & $40^{\circ} \mathrm{C} \times 72 \mathrm{hrs}$ & $+58 \%$ & $+71 \%$ & $+38 \%$ \\
Ethanol & $40^{\circ} \mathrm{C} \times 72 \mathrm{hrs}$ & $+3 \%$ & $-2 \%$ & $+10 \%$ \\
Gasohol & $40^{\circ} \mathrm{C} \times 72 \mathrm{hrs}$ & $+61 \%$ & $+59 \%$ & $+68 \%$ \\
\hline
\end{tabular}

A compression set measures the ability of rubber vulcanizates to retain their elastic properties after a prolonged constriction. A compression set is one of the essential properties of an elastomer for several industrial applications such as seals, gaskets, and O-rings, where dimensional stability of the parts is critical. In this study, compression set measurements were done over a wide range of temperatures, from $-30^{\circ} \mathrm{C}$ up to $150^{\circ} \mathrm{C}$, and Figure 5 shows the results. While measured at room temperature $\left(23^{\circ} \mathrm{C}\right)$, the compression set values are comparable among the rubbers studied here, ranging between 6 and $11 \%$. The extent of the compression set increases with cooling below the ambient temperature for all three rubbers. However, the compression set resistance of acrylonitrile-chloroprene rubber (NCR) is significantly better than that of NBR and CR while measured at $0^{\circ} \mathrm{C}$ or below. The NCR vulcanizate demonstrates less than $25 \%$ compression set up to $-20^{\circ} \mathrm{C}$, compared to a $+90 \%$ compression set in the vulcanizate of $\mathrm{CR}$ at/under $0^{\circ} \mathrm{C}$. Even though the NCR has a lower $T_{\mathrm{g}}\left(-24^{\circ} \mathrm{C}\right.$ as observed through DSC) than the $\mathrm{CR}$ homopolymer $\left(T_{\mathrm{g}}=-35^{\circ} \mathrm{C}\right)$, acrylonitrilechloroprene rubber offers a much lower compression set or better elastic recovery at subambient temperatures. At $-30^{\circ} \mathrm{C}$, the compression set of NCR worsens significantly, shooting up to more than $70 \%$, as the test temperature becomes a few degrees lower than the glass transition temperature of the elastomer itself. However, the CR homopolymer loses its elastic recovery almost entirely with a compression set of nearly $100 \%$ at even $0^{\circ} \mathrm{C}$. It is known that the changes in elastomers due to low temperatures are physical, not chemical. The lower temperatures (particularly the subambient temperatures) induce crystallization in the chloroprene rubber homopolymer, causing stiffening of the polymer. DSC results of CR, shown in Figure 3, evidenced crystallization. As a result, the compression set resistance of the $\mathrm{CR}$ homopolymer reduces drastically with lowering the temperatures from ambient. In acrylonitrile-chloroprene rubber, however, highly electronegative and bulky -CN groups hinder the folding of the polymer chains, preventing crystallization. Therefore, the low-temperature compression set property of noncrystallizing NCR is appreciably better than that of the CR homopolymer. As reported elsewhere, the $T_{\mathrm{g}}$ of NBR with $\sim 34 \% \mathrm{ACN}(\mathrm{N} 230 \mathrm{~S})$ is around $-20^{\circ} \mathrm{C}$ [29]. Therefore, with the temperature approaching $-20^{\circ} \mathrm{C}$, the compression set increases drastically in NBR.
In terms of compression set resistance at elevated temperatures $\left(100^{\circ} \mathrm{C}\right.$ onwards), the performance of NCR is marginally inferior but reasonably closer to that of CR. Both the elastomers demonstrate excellent high-temperature compression set properties. Even at $150^{\circ} \mathrm{C}$, both NCR and CR offer an under $40 \%$ compression set after $72 \mathrm{hrs}$. However, NBR shows an undesirably high (more than $60 \%$ ) compression set even at $120^{\circ} \mathrm{C}$. As expected, the compression set in NBR worsens as the test temperature increases, reaching $78 \%$ at $150^{\circ} \mathrm{C}$. In rubber compounds, the permanent deformation or compression set is attributed to uncrosslinked chains, which do not contribute to the permanent network and may relax or continue to crosslink during the compression, particularly at higher temperatures. The new crosslinks then prevent the stock from returning to its original shape. A strong correlation exists between the extent of crosslinking and the compression set [30]. The higher state of cure (or the higher crosslink density) in CR, as evidenced through the cure curve shown in Figure 4, likely contributes to its better compression set at elevated temperatures as compared to that in acrylonitrile-chloroprene rubber. NBR, beyond $100^{\circ} \mathrm{C}$, may undergo reform in crosslinking (polysulfide to $\mathrm{di} /$ monosulfide transformations) or even degradation of polymer chains. Typically, the irreversible chemical changes happening in NBR as it approaches its upper service temperature of about $100^{\circ} \mathrm{C}$ cause the rubber to become progressively rigid, reducing resistance to the compression set.

The results of dynamic mechanical thermal analysis (DMTA) of acrylonitrile-chloroprene rubber (NCR) vulcanizates are presented in Figure 6, along with that of CR and NBR. The storage (elastic) modulus, $E^{\prime}$; the loss (damping) modulus, $E^{\prime \prime}$; and the damping coefficient $(\tan \delta$ ), expressed as the ratio of $E^{\prime}$ and $E^{\prime \prime}$, are shown as a function of temperature over $-150^{\circ} \mathrm{C}$ to $150^{\circ} \mathrm{C}$. The intercept of the slopes in $E^{\prime}$ and the peaks of $E^{\prime \prime}$ and $\tan \delta$ correspond to the glass transition temperatures of the rubbers. DMTA results corroborate the observations found through DSC (Figure 3) of a positive shift of glass transition temperature in NCR as compared to CR. It can also be noticed that above the glass transition region, NCR has lower storage modulus and slightly higher loss modulus as compared to CR. This can be better viewed in the $\tan \delta$ plot. The higher damping coefficients found in NCR beyond the glass transition as compared to CR reflect its capability of better energy dissipation, which validates the improved flex-fatigue resistance of NCR over CR.

The resistance of acrylonitrile-chloroprene rubber (NCR) vulcanizates toward different test fluids was also evaluated and compared against that of CR and NBR. The fluids considered were ASTM reference oils: IRM 903 and IRM 901; Engine oil; Gasohol (a blend of 90\% gasoline and 10\% Ethanol); Ethanol; and ASTM reference fluid: Fuel C (a $50 \%$ by volume mixture of isooctane and toluene). Due to the higher volatility of the medium, the tests with Ethanol, Gasohol, and Fuel C were conducted at $40^{\circ} \mathrm{C}$ for $72 \mathrm{hrs}$. In relatively viscous fluids such as IRM 901, IRM 903, and Engine oil, the specimens were exposed to $130^{\circ} \mathrm{C}$ for $72 \mathrm{hrs}$. Resistance to different fluids in terms of changes in the volume of the samples after immersion for 72 hours is shown in Table 5. NCR exhibits appreciably lower swelling in IRM 903 (naphthenic 

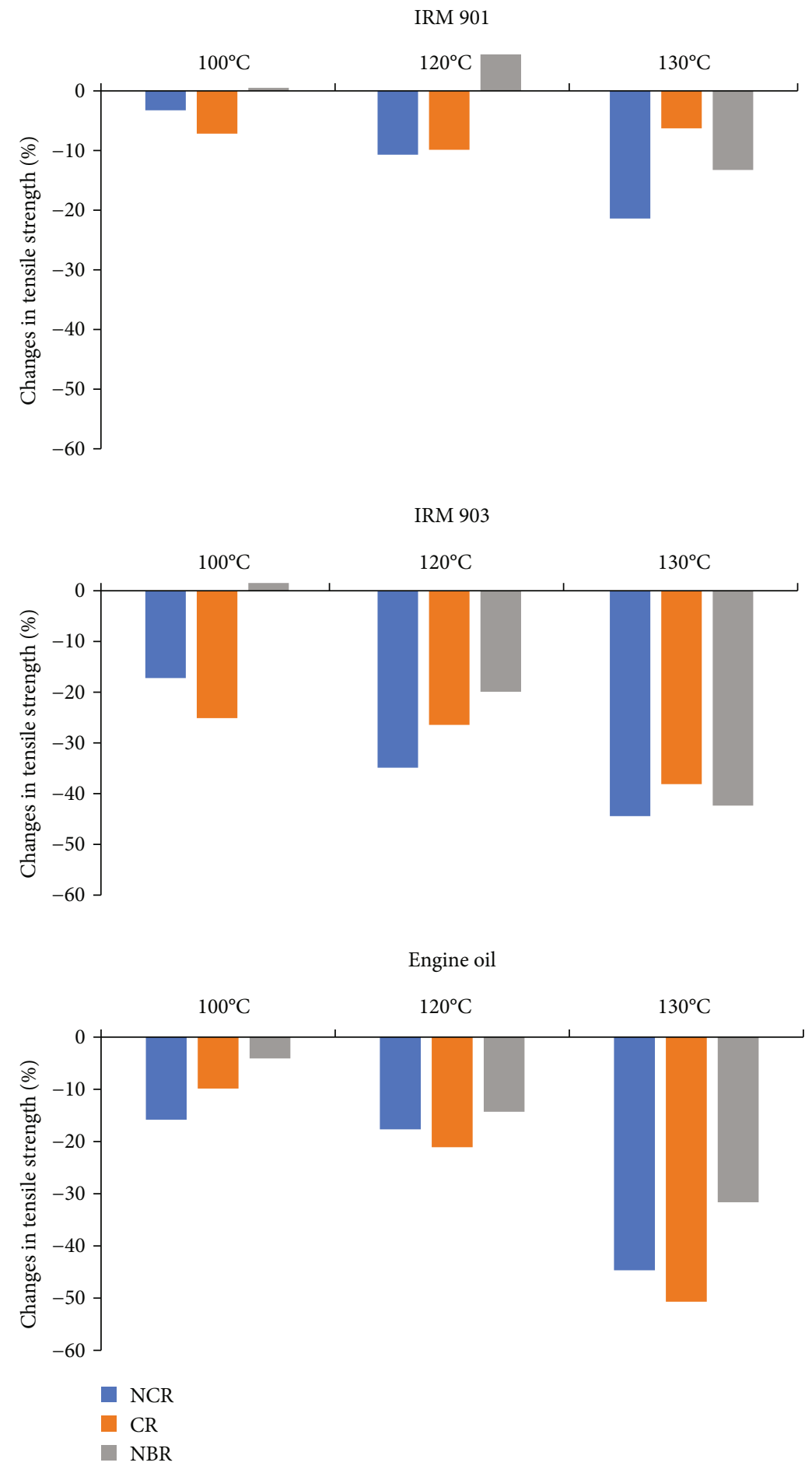

(a)

Figure 7: Continued. 

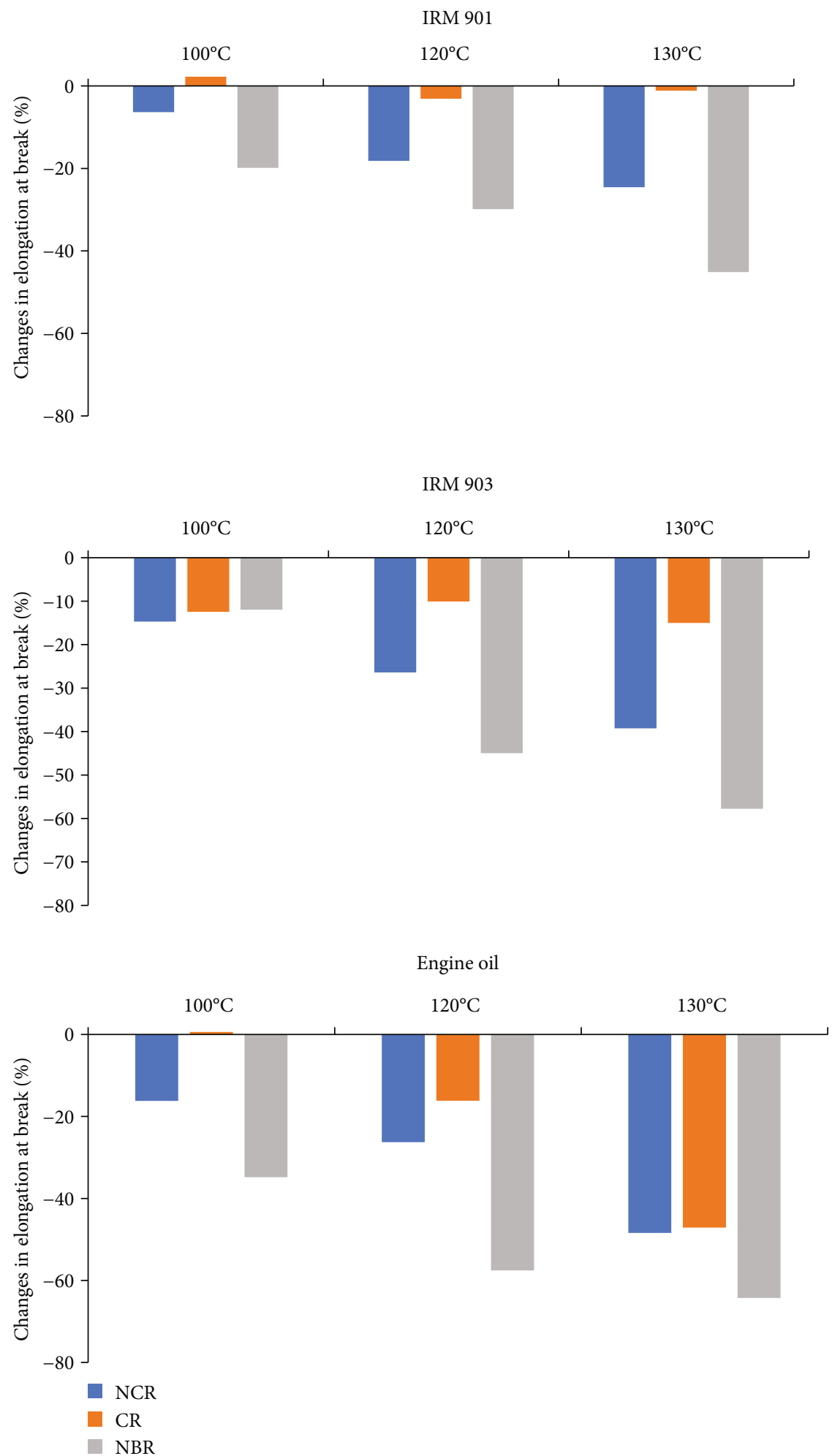

(b)

FIGURE 7: Changes in (a) tensile strength and (b) elongation at break of vulcanizates of acrylonitrile-chloroprene rubber (NCR), chloroprene rubber (CR), and nitrile rubber (NBR) as a function of temperature after $72 \mathrm{hrs}$ in different test oils.

base) and Fuel C, reflecting its better resistance than CR. NBR, however, demonstrates the least volume swelling in those two fluids, presumably due to its highest polarity among the three elastomers. In IRM 901 (paraffinic base),
Engine oil, and Ethanol, all three elastomers offer comparable and nominal volume changes (between 2 and 10\%). Both NCR and NBR reveal minor negative volume swelling or shrinkage in IRM 901 and Engine oil at $130^{\circ} \mathrm{C}$ after 72 hours, 

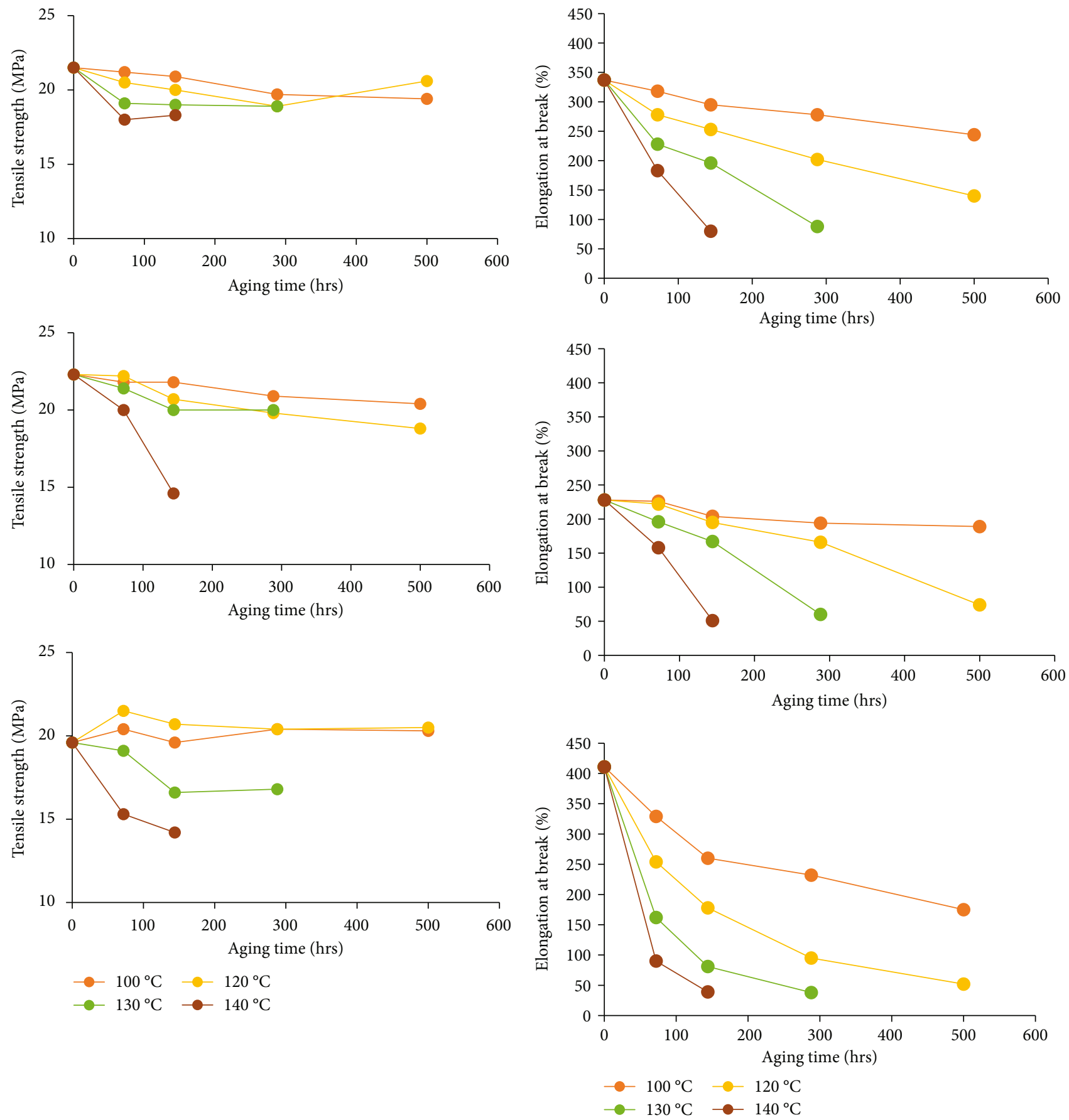

(a)

(b)

Figure 8: Continued. 

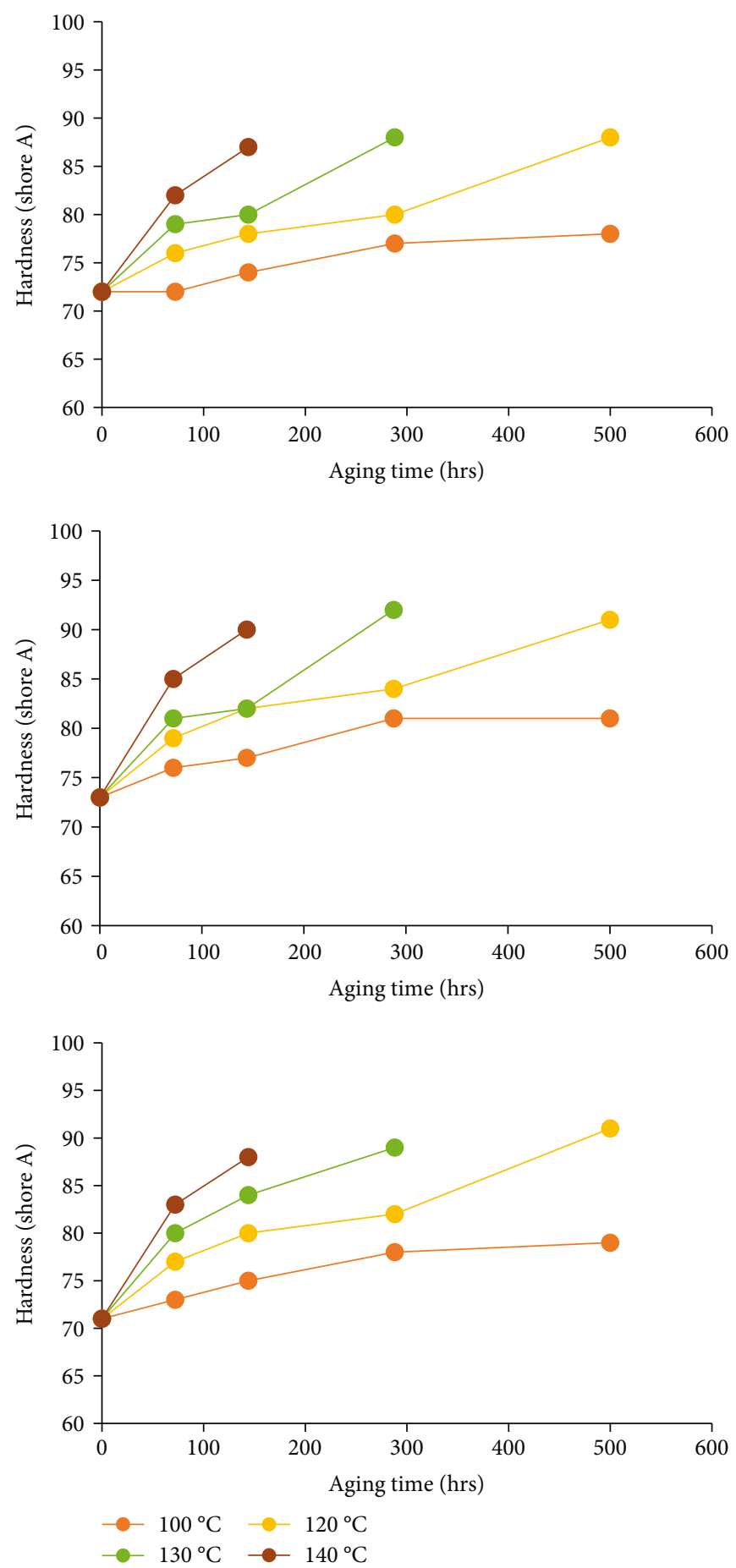

(c)

FIGURE 8: Effect of thermal aging on (a) tensile strength, (b) elongation at break, and (c) hardness of vulcanizates of acrylonitrile-chloroprene rubber (NCR), chloroprene rubber (CR), and nitrile rubber (NBR).

indicating susceptibility to the extraction of low-molecular weight components by the test fluids. The impact of Gasohol had been the most aggressive across all three rubbers, causing $60-70 \%$ volume swelling.

The influence of oils on the tensile properties was also assessed in IRM 901, IRM 903, and Engine oil at different temperatures, all exposed for 72 hours. We evaluated the impact of those oils on the percent changes of tensile strength and elongation at break values from that of preexposed specimens. The results are exhibited in Figures $7(a)$ and $7(b)$. The oil swelling causes loss of physical properties (plasticization effect) in all three elastomers but to different extents. Acrylonitrile-chloroprene rubber (NCR) specimens, after complete immersion into all the three test fluids even at 
TABLE 6: Ozone resistance of vulcanizates of acrylonitrilechloroprene rubber (NCR), chloroprene rubber (CR), and nitrile rubber (NBR).

\begin{tabular}{lccc}
\hline Exposure time & NCR & CR & NBR \\
\hline $24 \mathrm{hrs}$ & No crack & No crack & Cracks appear \\
$48 \mathrm{hrs}$ & No crack & No crack & \\
$72 \mathrm{hrs}$ & No crack & No crack & \\
$144 \mathrm{hrs}$ & Cracks appear & Cracks appear & \\
\hline
\end{tabular}

$130^{\circ} \mathrm{C}$, show more than $50 \%$ retention in elongation at break, which reflects their good resistance to hot fluids. CR shows the least change in properties irrespective of the temperatures and oils used. This could be linked to its highest crosslink density among all the elastomers tested. Interestingly for NBR, even though it shows the least swelling owing to its highest polarity, the changes in tensile properties are appreciable, particularly at higher temperatures. NBR offers good retention of tensile strength after $72 \mathrm{hrs}$ of immersion up to $120^{\circ} \mathrm{C}$. Above $120^{\circ} \mathrm{C}$, however, the tensile strength of NBR reduces drastically. In all three test fluids, the decline in elongation at break with temperature is most pronounced in $\mathrm{NBR}$, followed by NCR and CR. At $130^{\circ} \mathrm{C}$, the elongation at break values of NBR reduce by $45-64 \%$ regardless of the test fluids. The rapid deterioration in tensile properties of NBR at higher temperatures may be associated with polymer chain scissions induced by thermal degradation.

The thermal aging resistance of the three elastomer vulcanizates is compared by exposing the test specimens at different temperatures ranging from $100^{\circ} \mathrm{C}$ to $140^{\circ} \mathrm{C}$ for different periods, ranging from $72 \mathrm{hrs}$ to $500 \mathrm{hrs}$. The impact of thermal aging on tensile strength, elongation at break, and hardness values is shown in Figure 8 . As observed in Figures 8(a) and 8(c), acrylonitrile-chloroprene rubber (NCR) offers comparable heat resistance to CR in terms of changes in tensile strength and hardness, respectively. However, concerning the changes in elongation at break, CR performs slightly better than NCR, particularly at $100^{\circ} \mathrm{C}$ and $120^{\circ} \mathrm{C}$ (Figure 8(b)). However, that difference gets leveled off at severe aging conditions. At those conditions, the heat resistance of CR and NCR is comparable. For example, after $288 \mathrm{hrs}$ at $130^{\circ} \mathrm{C}$, the retentions of elongation at break are identical at $26 \%$ for both NCR and CR. NBR has the worst heat aging resistance among the elastomers evaluated here, in general. For NBR, up to $120^{\circ} \mathrm{C}$, the tensile strength increases with aging. After that (at $130^{\circ} \mathrm{C}$ and beyond), the tensile strength of NBR drops significantly with an increase in temperature or time. It has been reported that in thermooxidative aging of NBR, the crosslinking reaction dominates at the initial stage, causing the tensile strength to go up. As the aging progresses, the chain scission becomes significant, resulting in the rapid decrease of the tensile strength [31]. From early on, even at $100^{\circ} \mathrm{C}$, NBR shows an appreciable and steady decrease in elongation at break with time. Because of the presence of butadiene segments, NBR is quite easily oxidized and exhibits remarkable changes in properties with high-temperature aging. In both $\mathrm{CR}$ and acrylonitrile-chloroprene rubber (NCR), the pres- ence of electronegative chlorine deactivates the double bonds to some extent, thereby reducing the propensity toward thermooxidative degradations.

The ozone resistance results of the rubber vulcanizates are summarized in Table 6. In acrylonitrile-chloroprene rubber (NCR) and CR, the degradation caused by ozone becomes visible after $144 \mathrm{hrs}$ of exposure under identical test conditions. NBR, on the other hand, is far more susceptible to degradation by ozone. After just 24 hrs of ozone exposure, NBR specimens start showing surface cracks. The ozone-induced cracking in rubber is due to an electrophilic reaction and begins with the ozone attack at a location where the electron density is high [32]. In that respect, unsaturated organic compounds are typically reactive toward ozone. The unsaturated $-\mathrm{C}=\mathrm{C}$ - bonds are oxidized to $\mathrm{C}-\mathrm{O}$ bonds in the presence of ozone. The butadiene units of NBR are vulnerable to ozone, causing them to degrade early on with exposure. The electron-withdrawing effect of chlorine groups next to the $-\mathrm{C}=\mathrm{C}$ - in $\mathrm{CR}$ and acrylonitrilechloroprene rubber (NCR) renders the double bonds to be less reactive toward ozone resulting in their improved resistance to ozone as compared to NBR.

\section{Conclusion}

The qualitative characterizations of the newly developed acrylonitrile-chloroprene rubber (NCR) through infrared (FTIR) and nuclear magnetic resonance ( $\left.{ }^{1} \mathrm{H}-\mathrm{NMR}\right)$ confirmed the presence of $-\mathrm{Cl}$ and $-\mathrm{CN}$ groups in the copolymer. The single glass transition temperature, as evidenced through DSC and DMTA, reflected its monophasic random microstructure. Unlike the CR homopolymer, no low-temperature-induced crystallization was observed in acrylonitrile-chloroprene rubber, which may be due to the interference of bulky - $\mathrm{CN}$ groups preventing folding and specific alignment of polymer chains. NCR has slightly lower specific gravity than CR. While being cured using zinc oxide ( $\mathrm{ZnO}$ ) and trimethylthiourea (TMU) as an accelerator, NCR offered considerably better processing safety than CR. The acrylonitrile-chloroprene rubber vulcanizate shows lower modulus and slightly higher elongation at break, presumably associated with the lower crosslink density than CR. The tensile strength of NCR was marginally lower but reasonably comparable to CR. Tear strength and abrasion resistance of NCR and CR vulcanizates were almost equivalent, still slightly lesser than NBR vulcanized with sulfur. Acrylonitrile-chloroprene rubber vulcanizates demonstrated characteristically superior flex-fatigue resistance and an improved low-temperature compression set compared to the chloroprene rubber (CR) homopolymer. NCR vulcanizates also showed lower volume swelling in IRM 903 and Fuel $\mathrm{C}$ as compared to $\mathrm{CR}$, indicating improved fluid resistance. Acrylonitrile-chloroprene rubber vulcanizates offered appreciably lower heat buildup, higher flex-fatigue resistance, and much better heat aging and ozone resistance than NBR. The current assessment shows that acrylonitrile-chloroprene rubber can be a promising elastomer suitable for operating under both the static and dynamic loading conditions in 
applications where temperature tolerance and fluid resistance are concurrently required.

\section{Data Availability}

The test data on the properties of the new copolymer used to support the findings of this study are available from the corresponding author upon request.

\section{Conflicts of Interest}

The authors declare that they have no conflicts of interest.

\section{References}

[1] J. G. Speight, Handbook of Industrial Hydrocarbon Processes, Elsevier Inc, 2020.

[2] N. P. Cheremisinoff and P. N. Cheremisinoff, Elastomer Technology Handbook, CRC Press, 1st edition edition, 1993.

[3] J. Dunn, "Nitrile rubbers," in Encyclopedia of Materials: Science and Technology, K. J. Buschow, M. C. Flemings, E. J. Kramer, P. Veyssière, R. W. Cahn, B. Ilschner, and S. Mahajan, Eds., p. 6163, Elsevier, 2001.

[4] A. O. Patil and T. S. Coolbaugh, "Elastomers: a literature review with emphasis on oil resistance," Rubber Chemistry and Technology, vol. 78, no. 3, pp. 516-535, 2005.

[5] M. H. al-Maamori, A. I. al-Mosawi, and S. Abbas Abdulsada, "Effect of novolac nanoparticles additions on specific gravity of NBR/CR blends," MATEC Web of Conferences, vol. 178, article 04001, 2018.

[6] D. Q. Khang, T. K. Lien, L. N. Hai, D. Q. Minh, D. T. Sy, and L. H. Hai, "Study on preparation and properties of rubber blends based on nitrile butadiene rubber and chloroprene rubber," Macromolecular Symposia, vol. 384, no. 1, article 1800169, 2019.

[7] A. P. Kuriakose and M. Varghese, "The compounding of nitrile and polychloroprene rubbers with rice bran oil," Iranian Polymer Journal, vol. 8, no. 4, pp. 247-255, 1999.

[8] A. M. Omran, M. M. Ahmed, A. M. Youssef, and E. M. AbdelBary, "Effect of rubber blend compositions on their mechanical and oil resistance characteristics," The International Conference on Chemical and Environmental Engineering, vol. 4, no. 6, pp. 479-495, 2008.

[9] E. M. Abdel-Bary, W. von Soden, and F. M. Helaly, "Evaluation of the properties of some nitrile-butadiene rubber/polychloroprene mixes and vulcanizates," Polymers Advanced Technologies, vol. 11, no. 1, pp. 1-8, 2000.

[10] M. J. Azizli, S. Rezaeinia, K. Rezaeeparto, M. Mokhtary, and F. Askari, "Enhanced compatibility, morphology, rheological and mechanical properties of carboxylated acrylonitrile butadiene rubber/chloroprene rubber/graphene nanocomposites: effect of compatibilizer and graphene content," RSC Advances, vol. 10, no. 20, pp. 11777-11790, 2020.

[11] A. Das, K. W. Stöckelhuber, and G. Heinrich, "Influence of layered silicate on the self-crosslinking of polychloroprene and carboxylated nitrile rubber," Macromolecular Chemistry and Physics, vol. 210, no. 2, pp. NA-199, 2009.

[12] A. M. Omran, A. M. Youssef, M. M. Ahmed, and E. M. AbdelBary, "Mechanical and oil resistance characteristics of rubber blends based on nitrile butadiene rubber," Elastomere Und Kunststoffe, pp. 197-202, 2010.
[13] A. Nihmath and M. T. Ramesan, "Synthesis, characterization, processability, mechanical properties, flame retardant, and oil resistance of chlorinated acrylonitrile butadiene rubber," Polymers for Advanced Technologies, vol. 29, no. 8, pp. 2165-2173, 2018.

[14] A. Nihmath and M. Ramesan, "Comparative evaluation of oil resistance, dielectric properties, AC conductivity, and transport properties of nitrile rubber and chlorinated nitrile rubber," Progress in Rubber, Plastics and Recycling Technology, vol. 37, no. 2, pp. 131-147, 2021.

[15] W. Nishino, S. Onuki, K. Fujimoto, Y. Ishigaki, S. Hagiwara, and U. Yamagishi, "Method for producing statistical copolymer containing chloroprene monomer unit and unsaturated nitrile monomer unit, statistical copolymer, latex and use of same," 2020, US 2020/0199260 A1.

[16] K. Subramaniam, A. Das, and G. Heinrich, "Improved oxidation resistance of conducting polychloroprene composites," Composites Science and Technology, vol. 74, pp. 14-19, 2013.

[17] P. Y. le Gac, V. le Saux, M. Paris, and Y. Marco, "Ageing mechanism and mechanical degradation behaviour of polychloroprene rubber in a marine environment: comparison of accelerated ageing and long term exposure," Polymer Degradation and Stability, vol. 97, no. 3, pp. 288-296, 2012.

[18] T. Saito, S. Kawahara, and Y. Ohtake, "Assignment of NMR signals for chloroprene rubber by two-dimensional NMR spectroscopy," Rubber Chemistry and Technology, vol. 86, no. 2, pp. 250-260, 2013.

[19] H. Gottlieb, V. Kotlyar, and A. Nudelman, "NMR chemical shifts of common laboratory solvents as trace impurities," The Journal of Organic Chemistry, vol. 62, no. 21, pp. 75127515, 1997.

[20] D. Mileva, D. Tranchida, and M. Gahleitner, "Designing polymer crystallinity: an industrial perspective," Polymer Crystallization, vol. 1, no. 2, article e10009, 2018.

[21] M. Pöschl, S. Gopi Sathi, R. Stoček, and O. Kratina, "Rheometer evidences for the co-curing effect of a bismaleimide in conjunction with the accelerated sulfur on natural rubber/chloroprene rubber blends," Polymers, vol. 13, no. 9, p. 1510, 2021.

[22] H. Kato and H. Fujita, "Development of synergistic curing systems for polychloroprene," Rubber Chemistry and Technology, vol. 55, no. 4, pp. 949-960, 1982.

[23] J. Kruželák, A. Kvasničáková, and I. Hudec, "Peroxide curing systems applied for cross-linking of rubber compounds based on SBR," Advanced Industrial and Engineering Polymer Research, vol. 3, no. 3, pp. 120-128, 2020.

[24] W. V. Mars and A. Fatemi, "Factors that affect the fatigue life of rubber: a literature survey," Journal of Rubber Chemistry and Technology, vol. 77, no. 3, pp. 391-412, 2004.

[25] H. Chun and A. N. Gent, "Strength of sulfur-linked elastomers," Rubber Chemistry and Technology, vol. 69, no. 4, pp. 577-590, 1996.

[26] B. Rodgers, Rubber Compounding: Chemistry and Applications, CRC Press, Second Edition edition, 2016.

[27] L. Yang, K. Liu, and A. Du, “The effect of network structure on compressive fatigue behavior of unfilled styrene-butadiene rubber," Advances in Materials Science and Engineering, vol. 2020, Article ID 6729754, 9 pages, 2020.

[28] A. N. Gent and M. D. Ellul, "Mechanical fatigue," in Engineering with Rubber, How to Design Rubber Components, A. Gent, 
Ed., pp. 159-203, Carl Hanser Verlag, München, 3rd ed edition, 2012.

[29] M. Song, X. Zhao, Y. Li, T. W. Chan, L. Zhang, and S. Wu, "Effect of acrylonitrile content on compatibility and damping properties of hindered phenol AO-60/nitrile-butadiene rubber composites: molecular dynamics simulation," RSC Advances, vol. 4, no. 89, pp. 48472-48479, 2014.

[30] N. P. Cheremisinoff, Condensed Encyclopedia of Polymer Engineering Terms, Elsevier Inc., 2001.

[31] J. Zhao, R. Yang, R. Iervolino, and S. Barbera, "Changes of chemical structure and mechanical property levels during thermo-oxidative aging of NBR," Rubber Chemistry and Technology, vol. 86, no. 4, pp. 591-603, 2013.

[32] R. N. Datta, N. M. Huntink, S. Datta, and A. G. Talma, "Rubber vulcanizates degradation and stabilization," Rubber Chemistry and Technology, vol. 80, no. 3, pp. 436-480, 2007. 